Article

\title{
Prostaglandin D2-Mediated DP2 and AKT Signal Regulate the Activation of Androgen Receptors in Human Dermal Papilla Cells
}

\author{
Kwan Ho Jeong ${ }^{(\mathbb{D}}$, Ji Hee Jung ${ }^{(\mathbb{D}}$, Jung Eun Kim and Hoon Kang *(1) \\ Department of Dermatology, St. Paul's Hospital, College of Medicine, The Catholic University of Korea, \\ Seoul 02259, Korea; jaykh86@gmail.com or kwanho16@nate.com (K.H.J.); kpajjh@naver.com (J.H.J.); \\ mdkjeun@naver.com (J.E.K.) \\ * Correspondence: johnkang@catholic.ac.kr; Tel.: +82-2-958-2143; Fax: +82-2-969-8999
}

Received: 15 January 2018; Accepted: 9 February 2018; Published: 12 February 2018

\begin{abstract}
Prostaglandin D2 (PGD2) and prostaglandin D2 receptor 2 (DP2) is known to be an important factor in androgenetic alopecia (AGA). However, the effect of PGD2 in human dermal papilla cells (hDPCs) is not fully understood. The function of PGD2-induced expression of the androgen receptor (AR), DP2, and AKT (protein kinase B) signal were examined by using real time-PCR (qRT-PCR), western blot analysis, immunocytochemistry (ICC), and siRNA transfection system. PGD2 stimulated AR expression and AKT signaling through DP2. PGD2 stimulated AR related factors (transforming growth factor beta 1 (TGF $\beta 1$ ), Creb, lymphoid enhancer binding factor 1 (LEF1), and insulin-like growth factor 1, (IGF-1)) and AKT signaling (GSK3 $\beta$ and Creb) on the AR expression in hDPCs. However, these factors were down-regulated by DP2 antagonist (TM30089) and AKT inhibitor (LY294002) as well as DP2 knockdown in hDPCs decreased AR expression and AKT signaling. Finally, we confirmed that PGD2 stimulates the expression of AR related target genes, and that AKT and its downstream substrates are involved in AR expression on hDPCs. Taken together, our data suggest that PGD2 promotes AR and AKT signal via DP2 in hDPCs, thus, PGD2 and DP2 signal plays a critical role in AR expression. These findings support the additional explanation for the development of AGA involving PGD2-DP2 in hDPCs.
\end{abstract}

Keywords: androgen receptor; dermal papilla cell; prostaglandin D2; AKT; CRTH2/DP2

\section{Introduction}

Androgenetic alopecia (AGA) is the most common hair loss disorder in men. AGA is characterized by the replacement of thick terminal hair with fine small vellus hair on the genetic predisposition area of scalp such as frontal and vertex area [1]. The major pathologic changes of hair follicles in AGA are hair cycle dynamics which shows gradually shortening of anagen phase. $5 \alpha$-reductase plays the key role in dermal papillar cells for the transformation of testosterone $(\mathrm{T})$ to dihydrotestosterone (DHT). After strong binding of DHT to androgen receptors (AR), following cascade signaling alters hair growth and affected hair follicles are miniaturized after all [2,3]. However, the mechanisms underlying AGA are not fully understood.

Histopathologically, inflammatory cell infiltration around the follicular bulge is commonly found in AGA hair follicles [4]. Mahe et al. hypothesized that the inflammatory process in AGA is triggered by pro-inflammatory cytokines such as MCP-1, IL-6 and IL-8 [5]. These inflammatory reactions have attracted the interest of many researchers studying the underlying pathogenesis of AGA.

Cotsarelis and colleagues reported that the levels of prostaglandin D2 synthase (PTGDS) and its catalytic product, prostaglandin D2 (PGD2), were elevated in the balding scalp compared with the non-balding scalp of patients with AGA, as well as PGD2 inhibits mouse and human hair growth 
through DP2 [6]. The biological effects of PGD2 are usually mediated by its two G protein-coupled receptors (PGD2 receptor; PTGDR): prostaglandin receptor 1 (DP1) and prostaglandin receptor 2 (DP2, also known as chemoattractant homologous receptor expressed on Th2 cells; CRTH2). The induction of PGD2 could result from increased androgen levels, since androgens have been shown to stimulate PTGDS [7]. Some evidences suggest that PGD2 promotes the onset of catagen phase and decreased hair lengthening, leading to an increase in telogen follicles and miniaturization of the hair follicles, and PGD2 also inhibits hair follicle regeneration involved in wound healing $[6,8,9]$. These findings have demonstrated the effect of PGD2 on hair growth and its roles in AGA. However, our understanding of how the PGD2 pathway functions in DPCs of AGA remains limited. Thus, we focused on the expression of AR related genes by PGD2-DP2 at cellular level.

\section{Results}

\subsection{Prostaglandin D2 Receptor 2 (DP2) Antagonist Regulates Dihydrotestosterone (DHT)-Induced} Prostaglandin D2 (PGD2) Pathway

To determine whether DHT affects the PGD2 pathway, human dermal papilla cells (hDPCs) were treated with various doses of DHT for $24 \mathrm{~h}$. Treatment with $100 \mathrm{nM}$ DHT increased cyclooxygenase-2 (COX2), PTGDS and DP2 mRNA expression (Figure 1A-C). Moreover, the protein level of DP2 was increased by $100 \mathrm{nM}$ of DHT treatment at $3 \mathrm{~h}$ (1.4-fold) and $5 \mathrm{~h}$ (1.9-fold), respectively (Figure 1D). In addition, the levels of PGD2 receptor were significantly upregulated upon treatment with high concentrations of DHT, such as $100 \mathrm{nM}$ and $1000 \mathrm{nM}$ (Figure 1E). We next examined whether a DP2 antagonist affects AR expression. hDPCs were pretreated with TM30089 (DP2 antagonist) at $20 \mu \mathrm{M}$ for $1 \mathrm{~h}$ and then treated with $100 \mathrm{nM}$ DHT for $5 \mathrm{~h}$. Stimulation with TM30089 inhibited the upregulation of AR and DP2 (Figure 1F,G). Additionally, immunocytochemistry data showed that DHT-stimulated AR and DP2 expression was detected in the nucleus, and the expression of AR and DP2 in the TM30089-treated group was weaker than that in the DHT-treated group (Figure S1A,B).

A

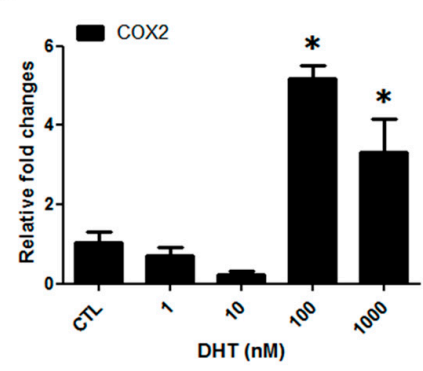

B

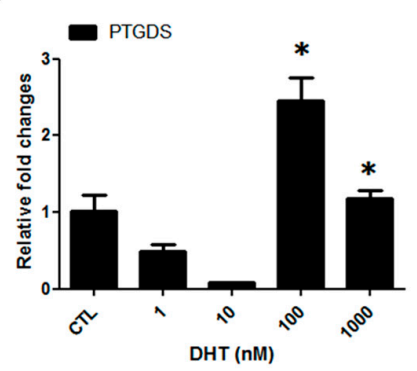

Figure 1. Cont.
C

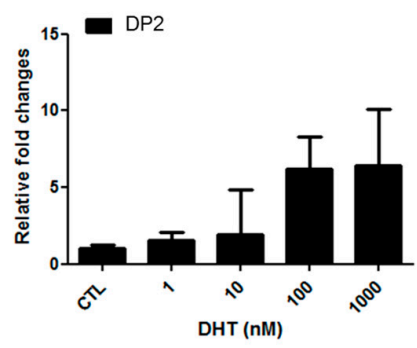


D
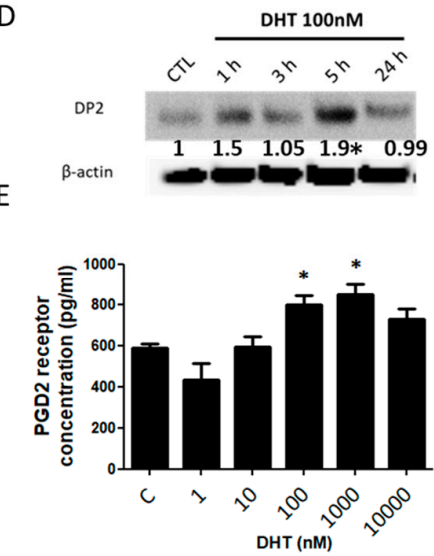
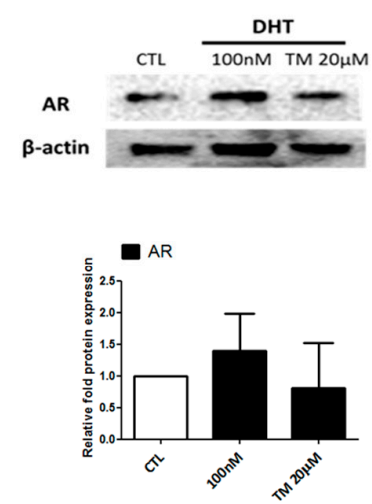

G
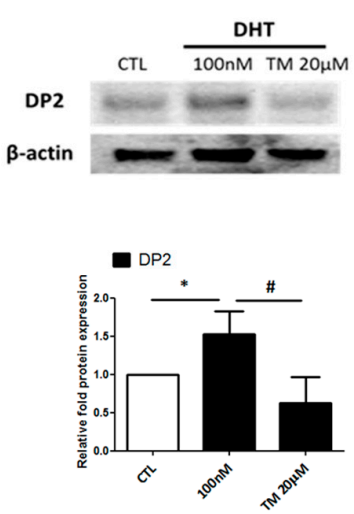

Figure 1. Prostaglandin D2 receptor (DP2) antagonist (TM30089) decreases dihydrotestosterone (DHT)-induced androgen receptor (AR) and prostaglandin expression in human dermal papilla cells (hDPCs). The mRNA expression of cyclooxygenase-2 (COX2), prostaglandin D2 synthase (PTGDS) and DP2 was examined in hDPCs treated with DHT for $24 \mathrm{~h}$. The mRNA expression of COX2 (A), PTGDS (B) and DP2 (C) was induced by $100 \mathrm{nM}$ DHT. DP2 protein expression was strongly induced by $100 \mathrm{nM}$ DHT at $5 \mathrm{~h}$ (D). hDPCs were cultured for $24 \mathrm{~h}$ with DHT, as indicated. The level of PGD2 receptor in the supernatant was evaluated in three independent experiments $(\mathrm{E})$. The relative mRNA levels were normalized to that of GAPDH. hDPCs were pretreated with $20 \mu \mathrm{M}$ TM30089 for $1 \mathrm{~h}$ and then treated with $100 \mathrm{nM}$ DHT for $5 \mathrm{~h}$. The protein level of AR (F) and DP2 (G) was measured by western blot. TM30089 decreased the DHT-induced AR and DP2 expression. $\beta$-actin served as a loading control for protein normalization. The results are expressed as the mean $\pm \mathrm{SD}$ of three independent experiments: CTL; control. ${ }^{*} p<0.05$ compared with the control ( $\left.0 \mathrm{nM} \mathrm{DHT}\right)$. \# $p<0.05$ compared with the DHT $100 \mathrm{nM}$.

\subsection{The Effects of PGD2 on AR Expression and hDPCs}

To determine whether PGD2 directly regulates AR expression, hDPCs were stimulated with various concentrations of PGD2 in serum-free medium for $24 \mathrm{~h}$. PGD2 at $50 \mathrm{nM}-1000 \mathrm{nM}$ induced the expression of AR. At $200 \mathrm{nM}$ in particular, PGD2 treatment increased the expression of AR (2.3-fold) mRNA at $24 \mathrm{~h}$ compared with $0 \mathrm{nM}$ group (Figure 2A). The mRNA expression of AR was increased at $24 \mathrm{~h}$ in compare with PGD2 treatment for $5 \mathrm{~h}$ group (Figure 2B). On the other hand, the protein level of $\mathrm{AR}$ was increased at $3 \mathrm{~h}$ and $5 \mathrm{~h}$ (Figure $2 \mathrm{C}$ ). We examined whether AR related factors are mediated by PGD2 in hDPCs. We observed that the mRNA expression of AR related factors (TGF $\beta 1$, Creb, LEF1, and IGF-1) was increased by PGD2 treatment (200 nM for $24 \mathrm{~h}$ ) (Figure 2D). We next examined whether PGD2 is involved in the growth inhibition of hDPCs. hDPCs were treated with various concentrations of PGD2 (0 nM-1000 nM) for $72 \mathrm{~h}$. PGD2 treatment dose-dependently inhibited cell viability at $72 \mathrm{~h}$ (Figure 2E). Furthermore, the mRNA expression of apoptosis-related genes, including caspase-1, -3 , and -9, was dose-dependently increased by PGD2 treatment for $24 \mathrm{~h}$ (Figure 2F). In addition, apoptosis in various concentration of PGD2 treated with hDPCs detected by TUNEL assay. We found that the number of apoptotic cells dose-dependently increased in the PGD2-treated groups (Figure S2A). Also, we examined the changes in protein levels of the Bcl2 and Bax genes, which are known to regulate apoptotic cell death. The Bax/Bcl2 ratio was 3.5-fold higher in the PGD2 (1000 nM) at 24 h compared with $5 \mathrm{~h}$ (Figure S2B). 

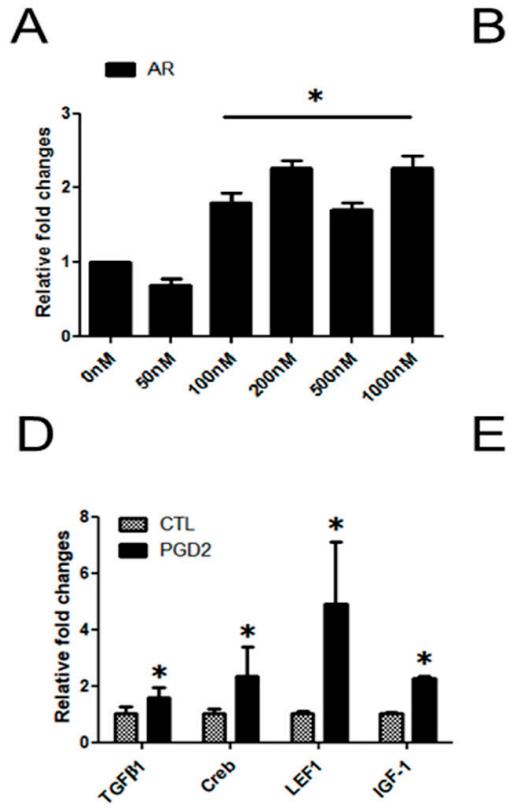

B

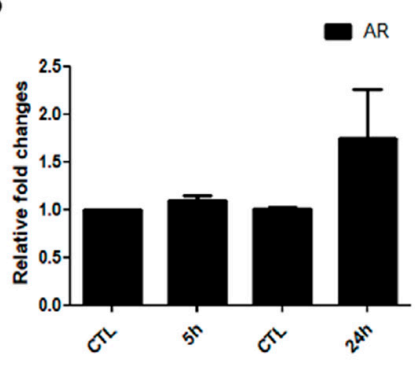

$E$

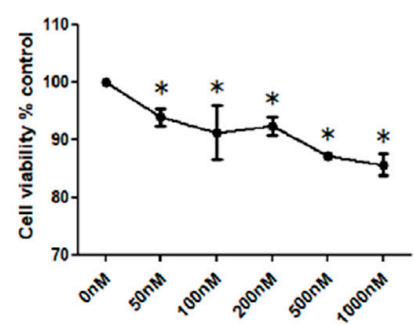

C

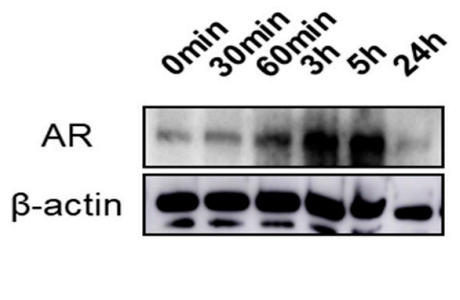

$\mathrm{F}$

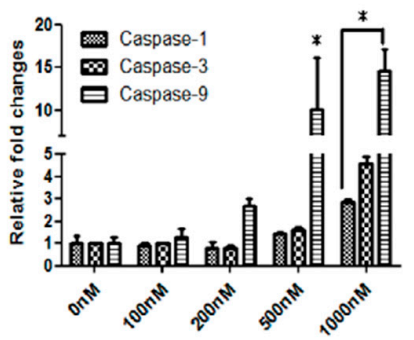

Figure 2. PGD2 regulates the AR expression and viability of hDPCs. hDPCs were cultured in serum-free DMEM for $24 \mathrm{~h}$, and then treated with the indicated concentrations of PGD2 for $24 \mathrm{~h}$ (A). For optimal condition of AR mRNA expression, hDPCs were cultured in serum-free DMEM for $24 \mathrm{~h}$, and then $200 \mathrm{nM}$ PGD2 treated in hDPCs for 5 and $24 \mathrm{~h}(\mathbf{B})$. hDPCs were treated with PGD2 (200 nM) for the indicated times and harvested. The AR protein level was determined using western blot analysis (C). The mRNA expression of transforming growth factor beta 1 (TGF $\beta 1$ ), Creb, lymphoid enhancer binding factor 1 (LEF1) and insulin-like growth factor 1 (IGF-1) was measured by qRT-PCR (D). Cell viability was determined using 3-(4,5-dimethylthiazol-2-yl)-2,5-diphenyl-2-H-tetrazolium bromide (MTT) assay after incubation with different concentrations of PGD2 (0, 50, 100, 200, 500, $1000 \mathrm{nM})$ for $72 \mathrm{~h}(\mathbf{E})$. The mRNA expression of caspase-1, -3 , and -9 was measured by qRT-PCR (F). The results are expressed as the mean $\pm \mathrm{SD}$ of three independent experiments. ${ }^{*} p<0.05$, compared with the control (0 nM PGD2).

\subsection{PGD2-Induced AR Expression is Regulated by AKT Signalling}

To investigate the association of the AKT and AR signalling pathways in PGD2-induced hDPCs, hDPCs were treated with PGD2 for different amounts of time, up to $24 \mathrm{~h}$. AKT phsphorylation was observed at 3 and $5 \mathrm{~h}$ (Figure 3A). Second, hDPCs were treated with LY294002 (AKT inhibitor) at $20 \mu \mathrm{M}$ for $1 \mathrm{~h}$ before AR, AKT and GSK3 $\beta$ (AKT/GSK3 $\beta$ ) phosphorylation was analysed using western blot. Stimulation with PGD2 increased AR and AKT/GSK3 $\beta$ phosphorylation in hDPCs compared with control. Treatment with LY294002 along with PGD2 further decreased AKT/GSK3 $\beta$ phosphorylation compared with PGD2 treated group (Figure 3B). We also examined the mRNA level of AR and AKT signal related factors LEF1, Creb, and IGF-1. All mRNA of examined molecules related to the AR were blocked by treatment with LY294002 (Figure 3C). 

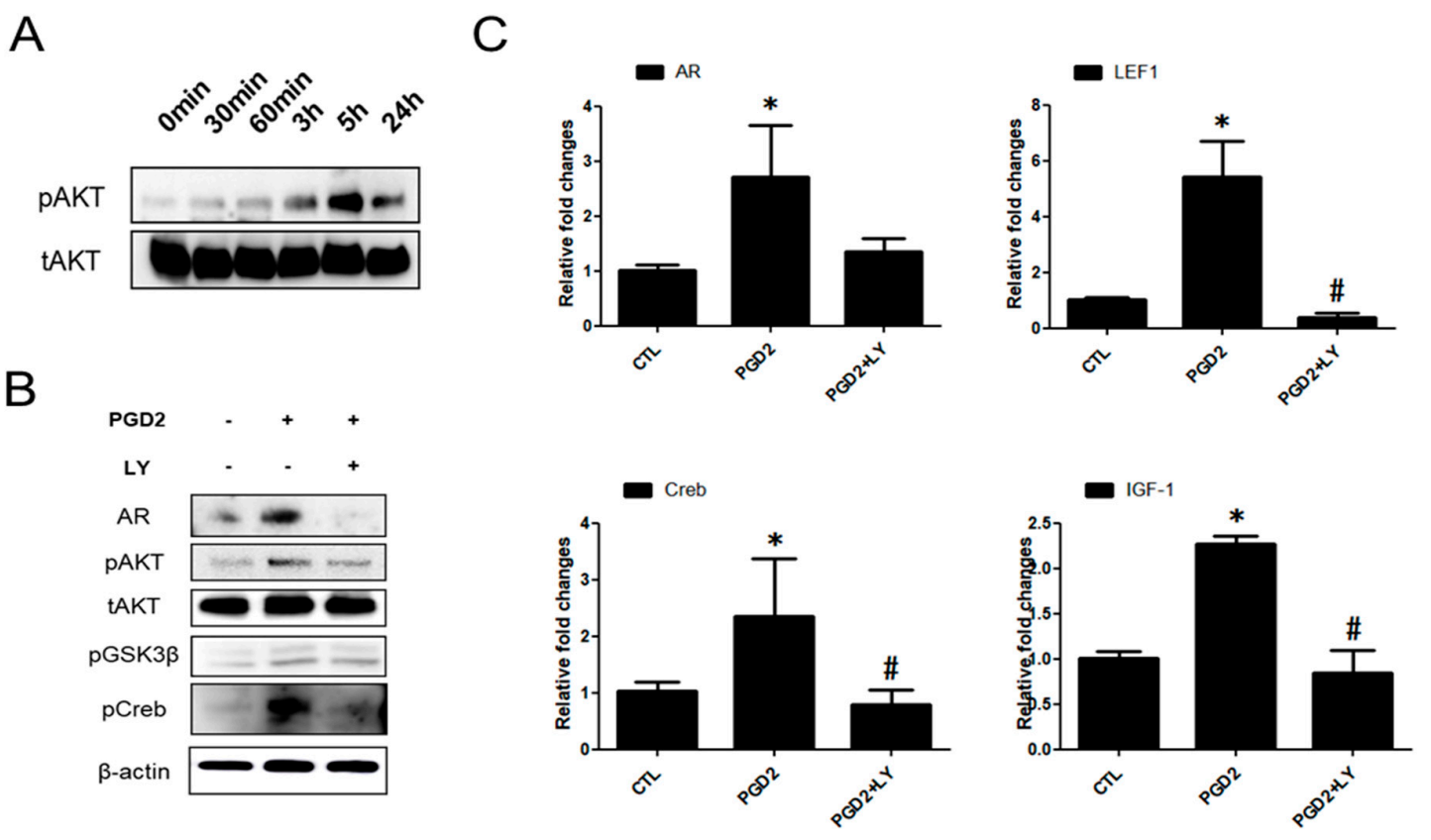

Figure 3. PGD2 regulates the AKT signal. The AKT phosphorylation was determined using western blot analysis. hDPCs were treated with PGD2 (200 nM) for the indicated times and harvested (A). hDPCs were pretreated with LY294002 for $1 \mathrm{~h}$, and then PGD2 (200 nM) treatment for $5 \mathrm{~h}$. The protein levels of $A R$, and AKT/GSK3 $\beta /$ Creb phosphorylation was measured using western blot analysis (B). The mRNA expression of AR, LEF1, Creb, and IGF-1 was measured using qRT-PCR (C). $\beta$-actin served as a loading control for protein normalization. GAPDH was used as an internal control for mRNA normalization. The results are expressed as the mean $\pm \mathrm{SD}$ of three independent experiments. ${ }^{*} p<0.05$, compared with the control (0 nM PGD2), \# $p<0.05$ compared with PGD2.

\subsection{PGD2-Induced AR Expression and AKT Signalling Are Regulated by a DP2 Antagonist}

We confirmed that PGD2-DP2 affects AR expression via AKT and its involved factors (including LEF1, Creb, and IGF-1). We hypothesized that suppression of DP2 would inactivate AR expression by inhibiting AR-related factors and AKT signalling. Thus, we examined whether inhibition of DP2 could regulate the activity of AR and its related factors. TM30089 has been known as a highly potent antagonist on mouse CRTH2/DP2 [10]. PGD2-induced AR, DP2, and COX2 mRNA expression was reduced by TM30089 (Figure 4A-C). We also found that the mRNA expression of TGF $\beta 1$, Creb, LEF1, and IGF-1, which are related to the activity of AR and AKT signalling, was blocked by TM30089 (Figure 4D-G). In addition, protein levels of AR and phosphorylation of AKT/GSK3 $\beta$ was also reduced by the TM30089. (Figure 4H). PGD2-inhibited cell viability was significantly recovered by $30 \%$ upon treatment with TM30089 compared with the PGD2-treated group (Figure 4I). These results indicated that AR expression and hDPC viability were regulated by PGD2 through DP2. 
A

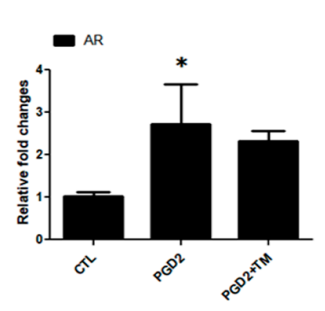

$E$

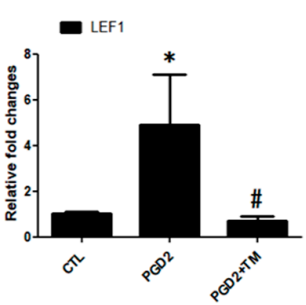

$\mathrm{H}$

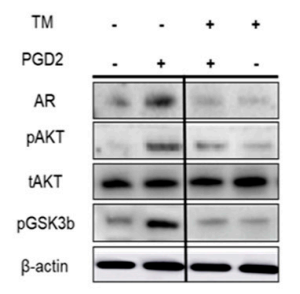

B

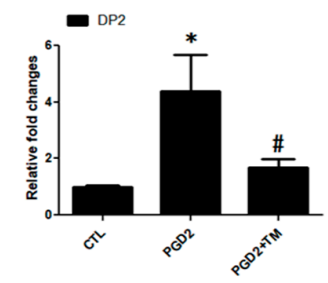

$\mathrm{F}$

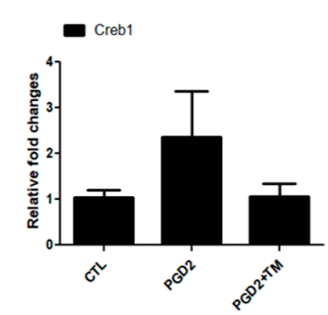

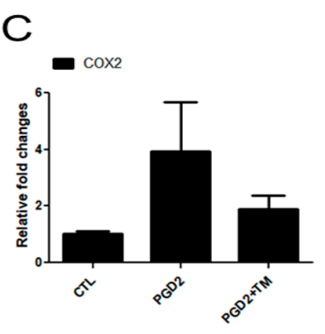

G
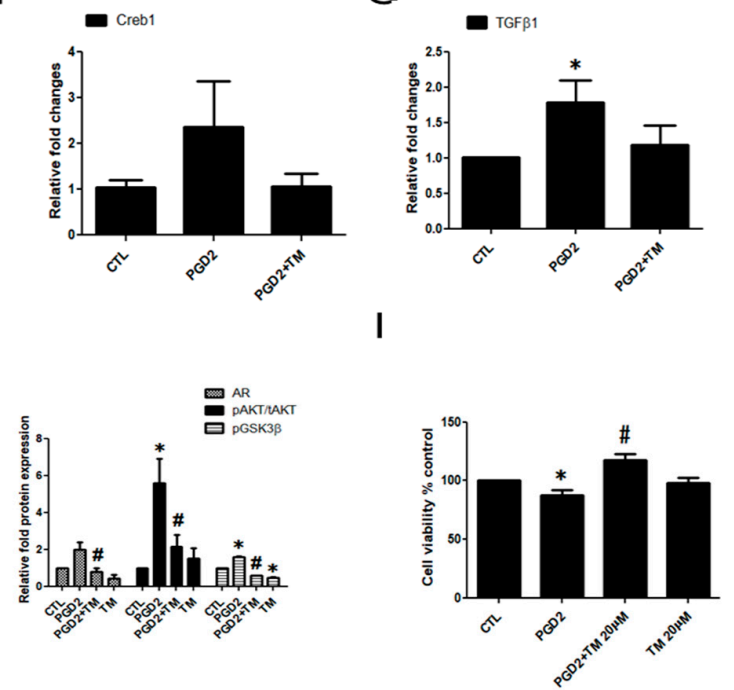

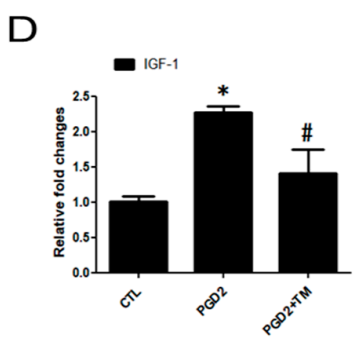

Figure 4. The effect of a DP2 antagonist on PGD2-induced AR related genes and AKT signalling in hDPCs. hDPCs were pretreated with TM30089 $(20 \mu \mathrm{M})$ or LY294002 $(20 \mu \mathrm{M})$ for $1 \mathrm{~h}$ and then stimulated with $200 \mathrm{nM}$ PGD2 for $24 \mathrm{~h}$. The mRNA expression of AR, DP2, COX2, IGF-1, LEF1, Creb, and TGF $\beta 1$ was measured by qRT-PCR (A-G). hDPCs in serum-free DMEM were pretreated with TM30089 $(20 \mu \mathrm{M})$ for $1 \mathrm{~h}$ and then stimulated with $200 \mathrm{nM}$ PGD2 for $5 \mathrm{~h}$. The protein level of $\mathrm{AR}$, and AKT/GSK3 $\beta$ phosphorylation was measured using western blot analysis. The histogram shows quantitative representation of the levels of PGD2-induced phosphorylation obtained from a densitometric analysis of three independent experiments $(\mathbf{H})$. An MTT-based assay was performed to determine the effects of PGD2 after $72 \mathrm{~h}$ of treatment. TM30089 $(20 \mu \mathrm{M})$ restored the viability of hDPCs that was inhibited by $200 \mathrm{nM}$ PGD2 (I). $\beta$-actin served as a loading control for protein normalization. GAPDH was used as an internal control for mRNA normalization. The results are expressed as the mean \pm SD of three independent experiments. TM; TM30089, * $p<0.05$ compared with the control (0 nM PGD2), \# $p<0.05$ compared with PGD2.

\subsection{The Functions of DP2 on PGD2-Induced AR Expression}

Next, to study the involvement of DP2 in PGD2-induced AR expression, hDPCs were transfected with DP2-targeting siRNA (20 nM). Transfection with DP2 siRNA significantly knocked down the protein level of AR, DP2, COX2 and AKT/GSK3 $\beta$ /Creb phosphorylation, whereas the negative control siRNA (siNC) (20 nM) had no effect (Figure $5 \mathrm{~A})$. We also confirmed DP2 gene silencing at the mRNA level. PGD2-induced the target of AR or AKT genes (including AR, COX2, DP2, LEF1, and Creb) and cell apoptosis genes such as caspase-3 and caspase- 9 were markedly attenuated by DP2-targeting siRNA transfection (Figure 5B). These data suggest that DP2 is important for PGD2-mediated AKT signal on AR expression in hDPCs. 
A

B
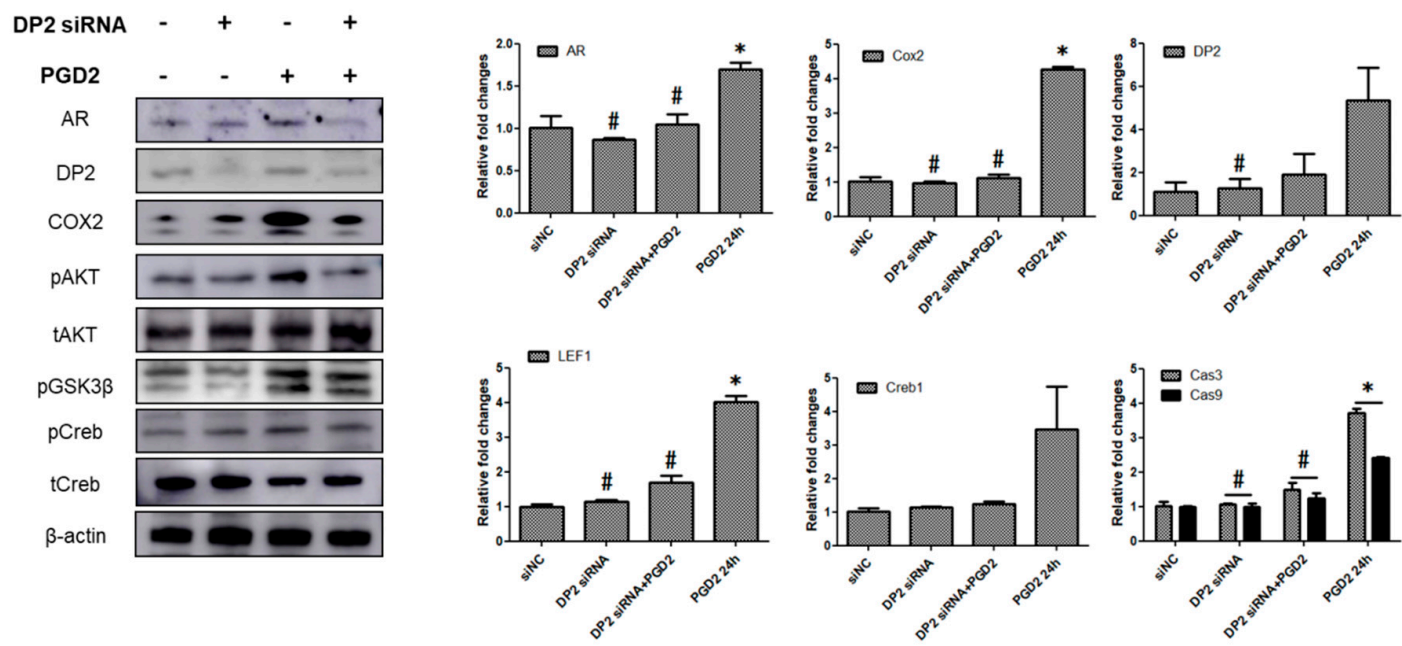

Figure 5. Knockdown of DP2 suppress AR related genes and AKT signal. After transfection with negative control (siNC) or DP2 siRNA, and then treated with PGD2 $(200 \mathrm{nM})$ for $5 \mathrm{~h}$. The protein levels of AR, DP2, COX2, and AKT/GSK3 $\beta /$ Creb phosphorylation was measured using western blot analysis (A). After transfection with siNA or DP2 siRNA for $24 \mathrm{~h}$, and then treated with PGD2 (200 nM) for $24 \mathrm{~h}$. The mRNA expression of AR, DP2, COX2, LEF1, Creb, and caspases (-3, and -9) was measured by qRT-PCR (B). $\beta$-actin served as a loading control for protein normalization. GAPDH was used as an internal control for mRNA normalization. The results are expressed as the mean $\pm \mathrm{SD}$ of three independent experiments. ${ }^{*} p<0.05$ compared with the siNC (siRNA negative control), $\# p<0.05$ compared with PGD2.

\section{Discussion}

Human dermal papilla cells (hDPCs) play an important role in hair follicle formation and hair regeneration and growth [11]. In particular, the regulation of growth and apoptosis in hDPCs has been reported to be necessary for maintaining hair growth [12]. Some studies have suggested that the factors secreted from hDPCs in response to DHT can induce male hair loss by affecting the activity of various genes in hair follicles $[13,14]$. DHT-induced androgens stimulate the secretion of hair growth inhibitory factors such as transforming growth factor beta 1 and 2 (TGF $\beta 1 / 2)[15,16]$. DHT is involved in several cellular signalling mechanisms. For example, DHT increases cell death and inhibits the cell cycle [12]. DHT modulates hair growth, hair cycling, and hair loss in AGA-susceptible hair follicles only [17]. Although definitive evidence has been reported for pathological mechanisms of AGA, the function of DPCs in AGA remain unclear.

DKK-1 and TGF $\beta 1$, which are cell death factors, are produced by DHT to destroy hair follicle cells and induce them to enter catagen stage, thereby causing hair loss [14,18]. Importantly, in susceptible individuals, DHT is also thought to precipitate an abbreviated anagen phase, as well as structural miniaturization in the hair follicle and associated anatomical structures.

Interestingly, DHT simulated prostaglandin D2 signalling through the expression of COX2, PTGDS, and DP2. Although various stimuli may induce the expression of COX2 in many cells [19,20], we used DHT, which promoted AR expression by affecting DP2 and COX2. We also investigated the changes the activity of AR by DP2 antagonist. Our results showed that DP2 antagonist has the potential to suppress AR signal by reducing the protein expression of DP2. These findings indicated that activation of AR is associated with DHT as well as prostaglandin pathway.

Cyclooxygenase-2 (COX2), a pro-inflammatory inducible enzyme, is a key enzyme in prostaglandin (PG) biosynthesis that converts arachidonic acid (AA) to PGG2 and subsequently to PGH2, which is metabolized by various PG synthases to other PGs [21]. PGs are potent biologically 
active lipid mediators that are produced from AA by almost every cell type and are known to regulate immune responses. One of them, PGD2 is involved in wound healing [8], and hair loss [6] actions are mediated through DP1 and CRTH2/DP2 [22]. We observed that DHT treatment enhanced the target of PGD2 pathway (COX2, PTGDS, and DP2) in hDPCs.

Based on the above results, we performed in vitro analysis to investigate the effect of PGD2 on the expression of AR in hDPCs. Firstly, we investigated the AR signal pathway involved in the effects of PGD2 in hDPCs. We focused on the TGF $\beta 1$ and TGF $\beta 2$, which involved in hair growth inhibition and apoptosis [14]. We also investigated the androgen specific transcription factors such as Creb, and LEF1, which plays an essential role in the regulation of prostate cancer cells; however, these factors have not been observed in the DPCs of hair follicles in AGA. Although IGF-1 was known as growth factor in hair development, some study reported that IGF-1 directly stimulated the activity of the $5 \alpha \mathrm{R}$ and AR [23]. We found that PGD2 treatment enhances the expression of AR, Creb, TGF $\beta 1$, IGF-1, and LEF1 mRNA. Although androgens did not alter the proliferation of hDPCs [11], our results showed that PGD2 did affect the viability of hDPCs. In similar to previous findings about the effect of PGD2 on cellular viability $[24,25]$, our results showed that at certain concentration, PGD2 can inhibit cell growth.

Apoptosis is related to the activation of caspases such as caspase- 3 and caspase-9. Caspase-9, an initiator caspase, can directly cleave and activate caspase-3 [26]. We found that PGD2 treatment significantly increased the expression of caspase-1, caspase- 3 and caspase- 9 at $24 \mathrm{~h}$. TUNEL is well known for effective method for detecting programmed cell death [27]. Our results showed that treatment with $1000 \mathrm{nM}$ of PGD2 caused a significant in the number of apoptosis hDPCs. PGD2 increased the expression of Bax (pro-apoptotic gene), while it caused a decrease in the expression of Bcl2 (anti-apoptotic gene) in hDPCs. These results indicate that cell apoptosis was induced by treatment with high concentration of PGD2, indicating the direct involvement of the caspase pathway.

Several studies have demonstrated that AKT is involved in signal transduction pathway downstream of a variety of inflammatory mediators, glycogen metabolism and proliferation apoptosis [28]. Phosphorylated AKT targets glycogen synthase kinase 3 (GSK3), subsequently phosphorylates GSK3 $\beta$ and GSK $3 \alpha$. Function of AKT and GSK3 $\beta$ were known as a key regulator of AR activation [29]. Activated GSK3 $\beta$ promoted the production of inflammatory molecules such as iNOS and COX2. Creb is regulated by a number of signaling kinase, including mitogen-activated protein kinase (MAPK) and AKT [30]. AKT signal that leads to induction of the AR in other cell systems [31]. Thus, we examined the role of AKT in PGD2-dependent signal pathway on AR expression in hDPCs. LY294002, a specific inhibitor of AKT, did affect the PGD2-induced upregulation of the AR, IGF-1, Creb, and LEF1 as well as phosphorylated AKT/GSK3 $\beta /$ Creb signal. We also observed that inhibition of AKT activation blocks the increases in expression of AR related genes induced by PGD2. Interestingly, according to previous studies, the knockdown of AKT/GSK3 $\beta$ suppressed AR related gene expression [32]. These results suggest that AKT/GSK3 $\beta$ phosphorylation is involved in AR expression. Although the role of PGD2-mediated AKT/GSK3 $\beta /$ Creb phosphorylation is uncertain in AR expression on hDPCs, our results indicated that PGD2-mediated AKT/GSK3 $\beta /$ Creb has been linked as a key factor in AR expression.

Based on the results of this study, PGD2-induced expression of AR might occur as a result of cell growth inhibition and various genes upregulation because of the activation of DP2. The DP2 antagonist TM30089 is known to regulate the viability of various cell types [10]. Thus, we observed that TM30089 has a reversal effect on the PGD2-induced decrease in cell viability. Besides, TM30089 did affect the PGD2-induced upregulation of the AR, DP2, and COX2 level as well as AKT/GSK3 $\beta /$ Creb phosphorylation level in hDPCs. In addition, the knockdown of DP2 (DP2 siRNA) on hDPCs did reduce the PGD2-induced AR, AKT and caspase pathway. These data indicated that AR expression of hDPCs by PGD2 was partly dependent on the presence of the DP2.

Taken together, we sought to determine which pathway(s) is critical for the induction of DP2 by PGD2 in hDPCs. Activation of DP2 by PGD2 leads to the AKT signal through G protein-dependent 
pathway, and more recent results show that activation of the DP2 induces apoptosis through the intrinsic pathway $[33,34]$.

\section{Materials and Methods}

\subsection{Human Dermal Papilla Cell (hDPCs) Culture and Reagents}

Human dermal papilla cells (hDPCs, sourced from scalp of a 57-old female) were purchased from PromoCell (Heidelberg, Germany). hDPCs were cultured in Follicle Dermal Papilla Cell Growth Media (PromoCell) supplemented with provided mixture reagent at $37^{\circ} \mathrm{C}$ in a humidified atmosphere of $5 \%$ $\mathrm{CO}_{2}$. Dihydrotestosterone (DHT) from Sigma-Aldrich (St. Louis, MO, USA). LY294002 (AKT inhibitor) were from Cell Signaling Technology (Beverly, MA, USA). TM30089 (DP2 antagonist) was from Caymen Chemical (Ann Arbor, MI, USA). For treatment, the reagents were dissolved in 100\% methanol and DMSO to a concentration at $10 \mathrm{mM}$. Three to fourth-passage DPCs were used in each experiment.

\subsection{Cell Viability Assay}

hDPCs were seeded in a 24-well plate at a density of $1 \times 10^{4}$ cells/well. To test whether DP2 antagonist participate in the viability of PGD2, hDPCs were seeded in a 24-well plate at a density of $1 \times 10^{4}$ cells/well. After $24 \mathrm{~h}$, the medium was replaced with serum-free medium. TM30089 $(20 \mu \mathrm{M})$ were pretreated with cells for $1 \mathrm{~h}$, and then incubated with or without $200 \mathrm{nM}$ of PGD2 for $72 \mathrm{~h}$. With the addition of $100 \mu \mathrm{L} /$ well of 3-(4,5-dimethylthiazol-2-yl)-2,5-diphenyl-2-H-tetrazolium bromide (MTT, Sigma) to each well, the cells were incubated at $37^{\circ} \mathrm{C}$ for $4 \mathrm{~h}$. Then, the supernatant was harvested and then treated with $400 \mu \mathrm{L}$ of dimethyl sulfoxide (DMSO, Sigma). The absorbance was measured at a wavelength of $570 \mathrm{~nm}$ using an enzyme-linked immunosorbent assay (ELISA, VersaMax Microplate, Thermo Fisher, MA, USA) reader.

\subsection{Real Time-PCR ( $q R T-P C R)$}

Total RNA from the hDPCs using the TRIzolTM reagent (Invitrogen, Carlsbad, CA, USA) and cDNA synthesis with QuantiTect Rev. Transcription kit (Qiagen, Hilden, Germany) according to the manufacturer's instructions. The cDNA used for real time-PCR, which was carried out with SYBR Green (Bio-Rad Laboratories, Inc., Hercules, CA, USA). The primers sequences and PCR conditions are listed in Supplementary Table S1.

\subsection{Western Blotting Analysis}

The protocol for western blot analysis was described in a previous report [35]. Briefly, the protein lysates from cultured hDPCs were prepared in RIPA cell lysis buffer containing protease inhibitor cocktail. The membranes were subsequently incubated with primary antibodies against total (AKT, $\mathrm{Creb}$ ) and phosphorylation (AKT, Creb, GSK3 $\beta$ ) (Cell Signaling Technology, Danvers, MA, USA), AR, COX2, Bax, Bcl-2 and $\beta$-actin (Santa Cruz Biotechnology, Inc., Santa Cruz, CA, USA), CRTH2/DP2 (Novus Biologicals LLC, Littleton, CO, USA) overnight at $4{ }^{\circ} \mathrm{C}$ on a rotary shaker.

\subsection{Immunofluoresence of Androgen Receptor and DP2}

hDPCs were plated in 8-chamber slides (SPL, Korea) at a density of $2 \times 10^{3}$ cells per well and cultured in serum-free medium in the presence of DHT or vehicle control (methanol) for $5 \mathrm{~h}$. Immunofluorescence staining of AR was performed as previously described [36]. Briefly, proteins were immunolabeled by incubating with anti-AR antibody (1:100, Cell Signaling Technology), anti-CRTH2/DP2 antibody (1:100, Novus) and anti-rabbit Alex Fluor 488 conjugated antibody (1:200; Invitrogen, OR, USA). Slides were examined under Axiovert 200 microscope (ZEISS, Germany). 


\subsection{ELISA}

PGD2 receptor ELISA kit (Abbexa, Cambridge, UK) was used according to the manufacturer's protocol. For the measurement of PGD2 receptor in conditioned medium of DHT-induced hDPCs, cells from passages 3-4 were plated overnight at a density of $2 \times 10^{5}$ cells per 6 well culture dish, washed three times with phosphate-buffered saline (PBS), and then incubated in serum-free medium for $24 \mathrm{~h}$ for the collection of conditioned medium. To examine PGD2 receptor induction in response to DHT in hDPCs were treated with varying concentrations of DHT in serum-free medium for 5 or $24 \mathrm{~h}$ and concentrations of PGD2 receptor in conditioned medium were measured. Optical density was measured by an ELISA reader at $450 \mathrm{~nm}$.

\subsection{DP2 Gene Silencing Experiments}

Small interfering RNA (siRNA) targeted at DP2 (Santa Cruz Biotechnology) was used to knockout DP2. hDPCs were cultured and incubated at $37^{\circ} \mathrm{C}$ in a $5 \% \mathrm{CO}_{2}$ incubator until $70-80 \%$ confluent. Thereafter, $2 \mu \mathrm{L}$ DP2 siRNA duplex was diluted into $100 \mu \mathrm{L}$ of siRNA transfection medium (Santa Cruz Biotechnology). In a separate tube, $2 \mu \mathrm{L}$ of transfection reagent (Santa Cruz biotechnology) was diluted into $100 \mu \mathrm{L}$ of siRNA transfection medium. The dilutions were mixed gently and incubated for $30 \mathrm{~min}$ at room temperature. Next, cells were incubated in negative control (siNC) or DP2 siRNA transfection cocktail for $5 \mathrm{~h}$ at $37^{\circ} \mathrm{C}$. Following transfection, media was changed in all cells to complete media and incubated for a further $18 \mathrm{~h}$. Effects of PGD2 on AR related genes and AKT signaling in normal and DP2-silenced hDPCs were then investigated.

\subsection{TUNEL Assay}

hDPCs seeded in 24-well plates at a density of $2 \times 10^{4}$ cell/well were treated with PGD2 at various concentrations $(0,200,500,1000 \mathrm{nM})$ or DMSO as a control for $72 \mathrm{~h}$. Cell apoptosis was examined with the in situ cell death detection kit (Roche, Mannheim, Germany) according to the manufacturer's instructions. The cells were fixed, permeated with $0.1 \%$ Triton X-100 solution, labelled for DNA breaks with terminal deoxynucleotide transferase (TdT) dUTP fluorescein nick end labeling (TUNEL, green fluorescence) and observed under Axiovert 200 microscope (ZEISS)

\subsection{Statistical Analysis}

All data are representative data from three independent experiments. The statistical significance of the differences among groups was tested using one-way ANOVA (SigmaPlot 12.3 software, San Jose, CA, USA). All graphs were generated using GraphPad Prism 5 (La Jolla, CA, USA). $p$ value $<0.05$ was considered statistically significant.

\section{Conclusions}

PGD2 directly stimulates the expression of androgen target genes, AKT and its downstream substrates are involved in mediating these effects. Thus, our data in this study provide that the activity of AR could be regulated not only DHT but also various signal changes by PGD2 in hDPCs.

Supplementary Materials: The following are available online at www.mdpi.com/1422-0067/19/2/556/s1.

Acknowledgments: This research was supported by the Ministry of Trade, Industry \& Energy (MOTIE), Korea Institute for Advancement of Technology (KIAT) through the Encouragement Program for The Industries of Economic Cooperation Region (R0005754).

Author Contributions: Kwan Ho Jeong and Ji Hee Jung performed the research, statistical analysed the data and wrote the manuscript. Jung Eun Kim conducted data collection, analysed and critically reviewed the study. Hoon Kang supervised the whole study process and wrote the manuscript. All authors contributed to this article.

Conflicts of Interest: The authors declare no conflict of interest. 


\section{References}

1. Sinclair, R. Male pattern androgenetic alopecia. BMJ 1998, 317, 865-869. [CrossRef] [PubMed]

2. Kaufman, K.D. Androgens and alopecia. Mol. Cell. Endocrinol. 2002, 198, 89-95. [CrossRef]

3. Sawaya, M.E.; Keane, R.W.; Blume-Peytavi, U.; Mullins, D.L.; Nusbaum, B.P.; Whiting, D.; Nicholson, D.W. Androgen responsive genes as they affect hair growth. Eur. J. Dermatol. 2001, 11, 304-308. [PubMed]

4. Magro, C.M.; Rossi, A.; Poe, J.; Manhas-Bhutani, S.; Sadick, N. The role of inflammation and immunity in the pathogenesis of androgenetic alopecia. J. Drugs Dermatol. 2011, 10, 1404-1411. [PubMed]

5. Mahe, Y.F.; Michelet, J.F.; Billoni, N.; Jarrousse, F.; Buan, B.; Commo, S.; Saint-Leger, D.; Bernard, B.A. Androgenetic alopecia and microinflammation. Int. J. Dermatol. 2000, 39, 576-584. [CrossRef] [PubMed]

6. Garza, L.A.; Liu, Y.; Yang, Z.; Alagesan, B.; Lawson, J.A.; Norberg, S.M.; Loy, D.E.; Zhao, T.; Blatt, H.B.; Stanton, D.C.; et al. Prostaglandin $\mathrm{D}_{2}$ inhibits hair growth and is elevated in bald scalp of men with androgenetic alopecia. Sci. Transl. Med. 2012, 4, 126ra34. [CrossRef] [PubMed]

7. Bhargava, S. Increased DHT levels in androgenic alopecia have been selected for to protect men from prostate cancer. Med. Hypotheses 2014, 82, 428-432. [CrossRef] [PubMed]

8. Nelson, A.M.; Loy, D.E.; Lawson, J.A.; Katseff, A.S.; Fitzgerald, G.A.; Garza, L.A. Prostaglandin $\mathrm{D}_{2}$ inhibits wound-induced hair follicle neogenesis through the receptor, Gpr44. J. Investig. Dermatol. 2013, 133, 881-889. [CrossRef] [PubMed]

9. Muller-Decker, K.; Leder, C.; Neumann, M.; Neufang, G.; Bayerl, C.; Schweizer, J.; Marks, F.; Furstenberger, G. Expression of cyclooxygenase isozymes during morphogenesis and cycling of pelage hair follicles in mouse skin: Precocious onset of the first catagen phase and alopecia upon cyclooxygenase- 2 overexpression. J. Investig. Dermatol. 2003, 121, 661-668. [CrossRef] [PubMed]

10. Uller, L.; Mathiesen, J.M.; Alenmyr, L.; Korsgren, M.; Ulven, T.; Hogberg, T.; Andersson, G.; Persson, C.G.; Kostenis, E. Antagonism of the prostaglandin $\mathrm{D}_{2}$ receptor CRTH2 attenuates asthma pathology in mouse eosinophilic airway inflammation. Respir. Res. 2007, 8, 16. [CrossRef] [PubMed]

11. Randall, V.A.; Hibberts, N.A.; Hamada, K. A comparison of the culture and growth of dermal papilla cells from hair follicles from non-balding and balding (androgenetic alopecia) scalp. Br. J. Dermatol. 1996, 134, 437-444. [CrossRef] [PubMed]

12. Winiarska, A.; Mandt, N.; Kamp, H.; Hossini, A.; Seltmann, H.; Zouboulis, C.C.; Blume-Peytavi, U. Effect of $5 \alpha$-dihydrotestosterone and testosterone on apoptosis in human dermal papilla cells. Skin Pharmacol. Physiol. 2006, 19, 311-321. [CrossRef] [PubMed]

13. Lee, M.J.; Cha, H.J.; Lim, K.M.; Lee, O.K.; Bae, S.; Kim, C.H.; Lee, K.H.; Lee, Y.N.; Ahn, K.J.; An, S. Analysis of the microRNA expression profile of normal human dermal papilla cells treated with $5 \alpha$-dihydrotestosterone. Mol. Med. Rep. 2015, 12, 1205-1212. [CrossRef] [PubMed]

14. Inui, S.; Itami, S. Molecular basis of androgenetic alopecia: From androgen to paracrine mediators through dermal papilla. J. Dermatol. Sci. 2011, 61, 1-6. [CrossRef] [PubMed]

15. Hibino, T.; Nishiyama, T. Role of TGF- $\beta 2$ in the human hair cycle. J. Dermatol. Sci. 2004, 35, 9-18. [CrossRef] [PubMed]

16. Tsuji, Y.; Denda, S.; Soma, T.; Raftery, L.; Momoi, T.; Hibino, T. A potential suppressor of TGF- $\beta$ delays catagen progression in hair follicles. J. Investig. Dermatol. Symp. Proc. 2003, 8, 65-68. [CrossRef] [PubMed]

17. Price, V.H. Androgenetic alopecia in women. J. Investig. Dermatol. Symp. Proc. 2003, 8, 24-27. [CrossRef] [PubMed]

18. Kwack, M.H.; Kim, M.K.; Kim, J.C.; Sung, Y.K. Dickkopf 1 promotes regression of hair follicles. J. Investig. Dermatol. 2012, 132, 1554-1560. [CrossRef] [PubMed]

19. Montserrat-de la Paz, S.; Bermudez, B.; Lopez, S.; Naranjo, M.C.; Romero, Y.; Bando-Hidalgo, M.J.; Abia, R.; Muriana, F.J. Exogenous fatty acids and niacin on acute prostaglandin $\mathrm{D}_{2}$ production in human myeloid cells. J. Nutr. Biochem. 2017, 39, 22-31. [CrossRef] [PubMed]

20. Wang, C.; Fu, M.; D’Amico, M.; Albanese, C.; Zhou, J.N.; Brownlee, M.; Lisanti, M.P.; Chatterjee, V.K.; Lazar, M.A.; Pestell, R.G. Inhibition of cellular proliferation through IкB kinase-independent and peroxisome proliferator-activated receptor $\gamma$-dependent repression of cyclin D1. Mol. Cell. Biol. 2001, 21, 3057-3070. [CrossRef] [PubMed] 
21. Kitz, K.; Windischhofer, W.; Leis, H.J.; Huber, E.; Kollroser, M.; Malle, E. 15-Deoxy- $\Delta^{12,14}$-prostaglandin $\mathrm{J}_{2}$ induces Cox-2 expression in human osteosarcoma cells through MAPK and EGFR activation involving reactive oxygen species. Free Radic. Biol. Med. 2011, 50, 854-865. [CrossRef] [PubMed]

22. Ricciotti, E.; FitzGerald, G.A. Prostaglandins and inflammation. Arterioscler. Thromb. Vasc. Biol. 2011, 31, 986-1000. [CrossRef] [PubMed]

23. Su, H.Y.; Hickford, J.G.; Bickerstaffe, R.; Palmer, B.R. Insulin-like growth factor 1 and hair growth. Dermatol. Online J. 1999, 5, 1. [PubMed]

24. Wu, C.C.; Shyu, R.Y.; Wang, C.H.; Tsai, T.C.; Wang, L.K.; Chen, M.L.; Jiang, S.Y.; Tsai, F.M. Involvement of the prostaglandin D2 signal pathway in retinoid-inducible gene 1 (RIG1)-mediated suppression of cell invasion in testis cancer cells. Biochim. Biophys. Acta 2012, 1823, 2227-2236. [CrossRef] [PubMed]

25. Harris, S.G.; Phipps, R.P. Prostaglandin $\mathrm{D}_{2}$, its metabolite $15-\mathrm{d}-\mathrm{PGJ}_{2}$, and peroxisome proliferator activated receptor- $\gamma$ agonists induce apoptosis in transformed, but not normal, human T lineage cells. Immunology 2002, 105, 23-34. [CrossRef] [PubMed]

26. Porter, A.G.; Janicke, R.U. Emerging roles of caspase-3 in apoptosis. Cell Death Differ. 1999, 6, 99-104. [CrossRef] [PubMed]

27. Soma, T.; Ogo, M.; Suzuki, J.; Takahashi, T.; Hibino, T. Analysis of apoptotic cell death in human hair follicles in vivo and in vitro. J. Investig. Dermatol. 1998, 111, 948-954. [CrossRef] [PubMed]

28. Liu, P.; Cheng, H.; Roberts, T.M.; Zhao, J.J. Targeting the phosphoinositide 3-kinase pathway in cancer. Nat. Rev. Drug Discov. 2009, 8, 627-644. [CrossRef] [PubMed]

29. Mulholland, D.J.; Dedhar, S.; Wu, H.; Nelson, C.C. PTEN and GSK3 $\beta$ : Key regulators of progression to androgen-independent prostate cancer. Oncogene 2006, 25, 329-337. [CrossRef] [PubMed]

30. Jasmin, B.J.; Gramolini, A.O.; Adatia, F.A.; Angus, L.; Boudreau-Lariviere, C.; Chan, R.Y.; Krupa, A.M.; Lunde, J.A.; Mankal, F.A.; Wu, J. Nerve-derived trophic factors and DNA elements controlling expression of genes encoding synaptic proteins in skeletal muscle fibers. Can. J. Appl. Physiol. 1998, 23, 366-376. [CrossRef] [PubMed]

31. Liao, R.S.; Ma, S.; Miao, L.; Li, R.; Yin, Y.; Raj, G.V. Androgen receptor-mediated non-genomic regulation of prostate cancer cell proliferation. Transl. Androl. Urol. 2013, 2, 187-196. [PubMed]

32. Liao, X.; Thrasher, J.B.; Holzbeierlein, J.; Stanley, S.; Li, B. Glycogen synthase kinase-3 $\beta$ activity is required for androgen-stimulated gene expression in prostate cancer. Endocrinology 2004, 145, 2941-2949. [CrossRef] [PubMed]

33. Yue, L.; Haroun, S.; Parent, J.L.; de Brum-Fernandes, A.J. Prostaglandin $\mathrm{D}_{2}$ induces apoptosis of human osteoclasts through ERK1/2 and AKT signaling pathways. Bone 2014, 60, 112-121. [CrossRef] [PubMed]

34. Kanda, N.; Ishikawa, T.; Watanabe, S. Prostaglandin $D_{2}$ induces the production of human $\beta$-defensin-3 in human keratinocytes. Biochem. Pharmacol. 2010, 79, 982-989. [CrossRef] [PubMed]

35. Ryu, S.; Lee, Y.; Hyun, M.Y.; Choi, S.Y.; Jeong, K.H.; Park, Y.M.; Kang, H.; Park, K.Y.; Armstrong, C.A.; Johnson, A.; et al. Mycophenolate antagonizes IFN- $\gamma$-induced catagen-like changes via $\beta$-catenin activation in human dermal papilla cells and hair follicles. Int. J. Mol. Sci. 2014, 15, 16800-16815. [CrossRef] [PubMed]

36. Choi, S.S.; Park, E.K.; Kwack, M.H.; Sung, Y.K. Effects of dexamethasone, a synthetic glucocorticoid, on human periodontal ligament stem cells. Naunyn-Schmiedeberg's Arch. Pharmacol. 2015, 388, 991-995. [CrossRef] [PubMed]

(C) 2018 by the authors. Licensee MDPI, Basel, Switzerland. This article is an open access article distributed under the terms and conditions of the Creative Commons Attribution (CC BY) license (http:// creativecommons.org/licenses/by/4.0/). 